\title{
Combined Dietary Action of Spirulina and Probiotics Mitigates Female Reproductive Ailments in Arsenicated Rats
}

\author{
Shamima Khatun ${ }^{1}$, Sudipta Chatterjee ${ }^{2}$ and Sandip Chattopadhyay ${ }^{1 *}$ \\ ${ }^{1}$ Department of Biomedical Laboratory Science and Management, and Clinical Nutrition and Dietetics division \\ (UGC Innovative Department), Vidyasagar University, Midnapore, West Bengal - 721102, India. ${ }^{2}$ Department of \\ Surgery, Midnapore Medical College and Hospital, Midnapore, West Bengal - 721102, India.
}

\begin{abstract}
Heavy metals contaminations in food and water are increased due to the environmental pollution. Managing arsenic toxicosis by dietary therapy is yet to be explored, although the conventional therapeutic strategy emphasizes the invasive chelating therapy. In this present study we elucidated the ameliorative effect of Spirulina and probiotics against arsenic-mediated female gonadal injury. The treatment was continued for 8 days ( 2 estrus cycles) on rats with sodium arsenite $(1.0 \mathrm{mg} / 100 \mathrm{~g}$ body weight) orally, but spirulina ( $40 \mathrm{mg} / 100 \mathrm{~g}$ body weight) and commercially available probiotics mixture $(2 \mathrm{mg} / 100 \mathrm{~g}$ body weight) were added in rat chow, fresh daily. Uterine and ovarian tissue experienced a significant impairment of antioxidant status, while a pronounced ovarian follicular degeneration was apparent from the increased number of follicular atresia in arsenic treated rats. All these deleterious effects of sodium arsenite were diminished significantly by spirulina and probiotics in arsenic fed rat. Moreover, an increase in the serum levels of of homocysteine ( $\mathrm{Hcy}$ ) in association with reduced serum levels of vitamin $B_{12}$ and folic acid were mitigated in arsenic fed rats following spirulina and probiotics dietary co-administration. However, the outcome of this study may indicate that spirulina and probiotics may be incorporated in the meal as nutraceuticals in limiting arsenic-mediated health hazards.
\end{abstract}

Keywords: Anti-oxidant, Arsenic, Oxidative stress, Uterus, Vitamin $B_{12}$.

*Correspondence: sandipdoc@mail.vidyasagar.ac.in

(Received: 25 January 2019; accepted: 05 March 2019)

Citation: Shamima Khatun, Sudipta Chatterjee and Sandip Chattopadhyay, Combined Dietary Action of Spirulina and Probiotics Mitigates Female Reproductive Ailments in Arsenicated Rats, J Pure Appl Microbiol., 2019; 13(2):1175-1184. doi: 10.22207/ JPAM.13.2.57

(c) The Author(s) 2019. Open Access. This article is distributed under the terms of the Creative Commons Attribution 4.0 International License which permits unrestricted use, sharing, distribution, and reproduction in any medium, provided you give appropriate credit to the original author(s) and the source, provide a link to the Creative Commons license, and indicate if changes were made. 


\section{INTRODUCTION}

Arsenic exposure causes noticeable damage in various organs, including male reproductive malfunction as manifested by reduced androgenesis, inhibition of spermatogenesis, and diminution in the weight of testes and other sex organs ${ }^{1}$. Several epidemiologic studies have been reported that arsenic exposure can cause the reproductive and developmental toxicity in animals and increased spontaneous abortion and stillbirth and loss of birth weight ${ }^{2}$. Moreover, arsenic exposure also has been associated with the inhibition of ovarian steroidogenesis and gonadotrophins secretion ${ }^{3}$. This experiment has been performed to search out the protective effect of dietary administered spirulina and probiotics in the mitigation of the arsenic mediated toxicity on female reproductive organs. Phycocyanin $(\mathrm{Pc})$ is a biliprotein of this blue-green alga spirulina. This protein contains a tetrapyrrole phycocyanobilin, which is responsible for antioxidant properties of $\mathrm{Pc}^{4}$. It has been reported that $\mathrm{Pc}$ has significant antioxidant and radical scavenging properties, offering protection against oxidative stress ${ }^{5}$. In addition, spirulina plays a protective role against arsenic toxicity in human ${ }^{6}$.

Probiotics are live microorganisms which contribute many health benefits to the host when administered in adequate amounts ${ }^{7}$. Lactic acid bacteria could prevent ROS production, including peroxide radicals ${ }^{8}$, superoxide anions, and hydroxyl radicals ${ }^{9}$. Considering the above background, this study was proposed towards the evaluation of the non-invasive dietary application of spirulina and probiotics against arsenic-induced uterine and ovarian toxicity.

\section{MATERIALS AND METHODS \\ Experimental design}

Fourty two female albino Wistar strain rats 60 days of age, weighing $110 \pm 5 \mathrm{~g}$ were selected in this experiment. All the rats were maintained in a controlled environment for 8 days for acclimatization in a room with a 12 -hour light-dark cycle, with $32 \pm 2^{\circ} \mathrm{C}$ temperatures and $50-70 \%$ humidity and were fed with standard pellet and water.

Treatment, study of estrous cycle and sample collection

Total 42 rats were equally distributed into seven groups. This experiment was continued for 8 days, and rats were treated with spirulina and probiotics with normal rat chow following the institutional ethical guidelines. Rats were distributed in seven groups. Each group contains six rats. Group I was vehicle-treated control, group II was sodium arsenite treated $(1.0 \mathrm{mg} / 100 \mathrm{~g}$ body weight), group III was considered as spirulina placebo group ( $40 \mathrm{mg} / 100 \mathrm{~g}$ body weight) (WestCoast Pharmaceutical Ahmedabad, Gujrat), group IV was given the same dose of sodium arsenite, along with spirulina, group $V$ was considered as probiotics placebo group $(2 \mathrm{mg} / 100 \mathrm{~g}$ body weight), group VI was treated with arsenic (1.0 $\mathrm{mg} / 100 \mathrm{gm}$ body weight) + Probiotics and group VII was administered with same dose of arsenic along with same dose of spirulina and probiotic supplement.

In this experiment we used commercially available probiotics powder. A $100 \mathrm{mg}$ of probiotics cocktail contains following composition:

Lactobacillus acidophilus - $13.714 \times 10^{7} \mathrm{CFU}$, Lactobacillus rhamnosus - $13.714 \times 10^{7} \mathrm{CFU}$, Bifidobacterium longum - $13.714 \times 10^{7} \mathrm{CFU}$, Bifidobacterium bifidum - $13.714 \times 10^{7} \mathrm{CFU}$, Saccharomyces boulardii - $2.857 \times 10^{7} \mathrm{CFU}$,

Above probiotics were mixed in normal diet, fresh daily. In this experimental study arsenic was fed to the rats via oral gavage of (group II, IV, $\mathrm{VI}$ and VII) for eight 8 days. The Spirulina platensis tablet $(500 \mathrm{mg}$, West-Coast Pharmaceutical, Ahmedabad, Gujarat) was crushed to produce dust. Spirulina (40 mg/100g body weight) and commercially available probiotics mixture ( 2 $\mathrm{mg} / 100 \mathrm{~g}$ body weight) were mixed in rat chow, fresh daily. The body weights and feeding habits of animals were recorded during the entire treatment schedule. The pattern of estrous cycle was observed regularly. On day 9 , the rats were anesthetized to collect blood and female organs. Determination of uterine oxidative stress markers and antioxidant enzymes

By standard technique of Devasagayam et al. 2003 MDA was determined ${ }^{10}$. The CD was measured as per the method where lipids were extracted by chloroform and methanol mixture ${ }^{11}$. Uterine SOD, catalase and GPx activities were measured following the previous method ${ }^{12-14}$.

Assessment of antioxidant enzymes and LDH by native gel electrophoresis 
Based on the principle of inhibition of the reduction of Nitro blue Tetrazollium chloride (NBT), the activity of SOD on $12 \%$ gel was assessed. To evaluate catalase activity $60 \mu \mathrm{g}$ proteins were electrophoresed on $8 \%$ PAGE using uterine tissue extract ${ }^{15}$. $8.0 \%$ native gel was used for the determination of GPx activity. The activity of GPx was determined by the removal of peroxide that was essential for the transformation of potassium ferricyanide to ferrocyanide between samples ${ }^{16}$. For the detection of serum lactate LDH $8.0 \%$ agarose gel was used ${ }^{17}$.

Vitamin $B_{12}$, Folic acid, Homocysteine analysis

Serum levels of $B_{12}$ (Cat no.ER1579)

Folic acid (Cat no.EU0381) Homocysteine

(Cat no.ER1509) were measured by ELISA kits according to the procedures recommended by the manufacturers (Wunhan Fine test, China).

Serum ES and uterine ER- $\alpha$ analysis and Ovarian and Uterine Histopathology

ES was determined based on the technology of Competitive-ELISA and ER- $\alpha$ was determined based on the technology of sandwich ELISA according to the procedures recommended by the Wunhan Fine test, China. The concentration of ES and ER- $\alpha$ in the samples was measured at a wavelength of $450 \mathrm{~nm}$. The ovarian and uterine section $(5.0 \mu \mathrm{m}$ thick paraffin embedded) were stained using hematoxylin (Harris) and eosin and observed under microscope (Olympus, CX21i, magnification $\times 400$ ).

\section{Statistical analysis}

In this experiment data were expressed in terms of mean $\pm \mathrm{SE}$, $(\mathrm{N}=6)$ of different groups. Differences in these variables between treated and control groups were evaluated using ANOVA followed by post hoc Dunnett t-test.

\section{RESULTS}

\section{General Observations}

No significant difference was found between the groups considering the animals' water intake (Table1). No significant changes of body weight among the experimental animals in seven groups were observed throughout the experiment. A significant weight loss of ovaries and uterus was observed in arsenic treated group (Table 1).

\section{Vaginal smear study}

Estrous cycles were noted regularly for 8 days. In due course of arsenic treatment of arsenic rats were remained in a consistent diestrus or metestrus after 4 days of treatment. The estrous phase was synchronized in control, spirulina and probiotics group.

\section{Status of oxidative stress markers}

There was a significant elevation in the uterine MDA and CD level in the sodium arsenite treated group in comparison to the control group (Table 2). A significant restoration of soluble thiol was observed in spirulina and probiotics supplemented group (Table 2).

Table 1. Body weight and organo-somatic indices (female reproductive organs)

\begin{tabular}{|c|c|c|c|c|c|}
\hline & \multicolumn{2}{|c|}{$\begin{array}{c}\text { Body Weight } \\
\text { (g) }\end{array}$} & \multicolumn{2}{|c|}{$\begin{array}{l}\text { Organo-somatic indices } \\
\text { (g) }\end{array}$} & \multirow[t]{2}{*}{$\begin{array}{l}\text { Water Intake } \\
\text { (ml) }\end{array}$} \\
\hline & Initial & Final & Ovary in pair & Uterus & \\
\hline Control & $85.2 \pm 3.7$ & $102 \pm 3.1$ & $0.05 \pm 0.002$ & $0.16 \pm 0.003$ & $9.8 \pm 1.3$ \\
\hline Arsenic & $91.4 \pm 5.8$ & $108.4 \pm 6.7$ & $0.04 \pm 0.002 * * *$ & $0.1 \pm 0.004 * * *$ & $14.9 \pm 0.6 * * *$ \\
\hline Spirulina & $93.8 \pm 6.9$ & $105 \pm 6.4$ & $0.06 \pm 0.001 \# \# \#$ & $0.14 \pm 0.003 * * \# \# \#$ & $8.7 \pm 0.4 \# \# \#$ \\
\hline Arsenic + Spirulina & $91.4 \pm 3.3$ & $107 \pm 4.6$ & $0.05 \pm 0.009 \# \# \#$ & 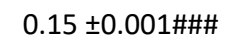 & $9.05 \pm 0.6 \# \# \#$ \\
\hline Probiotics & $91.2 \pm 3.8$ & $105.4 \pm 4.8$ & $0.05 \pm 0.008 \# \# \#$ & $0.16 \pm 0.001 \# \# \#$ & $8.9 \pm 0.3 \# \# \#$ \\
\hline Arsenic+Probiotics & $87.6 \pm 2.2$ & $101 \pm 4.0$ & $0.05 \pm 0.001 \# \# \#$ & $0.15 \pm 0.002 \# \# \#$ & $9.9 \pm 0.7 \# \# \#$ \\
\hline $\begin{array}{l}\text { Arsenic }+ \text { Spirulina+ } \\
\text { Probiotics }\end{array}$ & $87.4 \pm 2.8$ & $102.8 \pm 2.2$ & $0.05 \pm 0.001 \# \# \#$ & $0.13 \pm 0.003 * \# \# \#$ & $9.2 \pm 0.1 \# \# \#$ \\
\hline
\end{tabular}

The changes of body growth and organo-somatic indices in response to sodium arsenite ingestion and the protection of the changes by spirulina and probiotics were shown. The data are mean $\pm S E, N=6$, ANOVA followed by Post Hoc Dunnett test to find out statistical significance at $* p<0.05$. In addition, data were compared with As3+ and As3++ Spirulina, As3+ + Probiotics, As3+

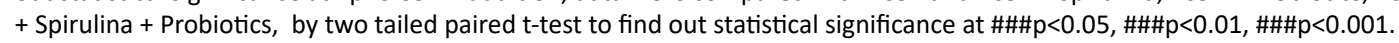




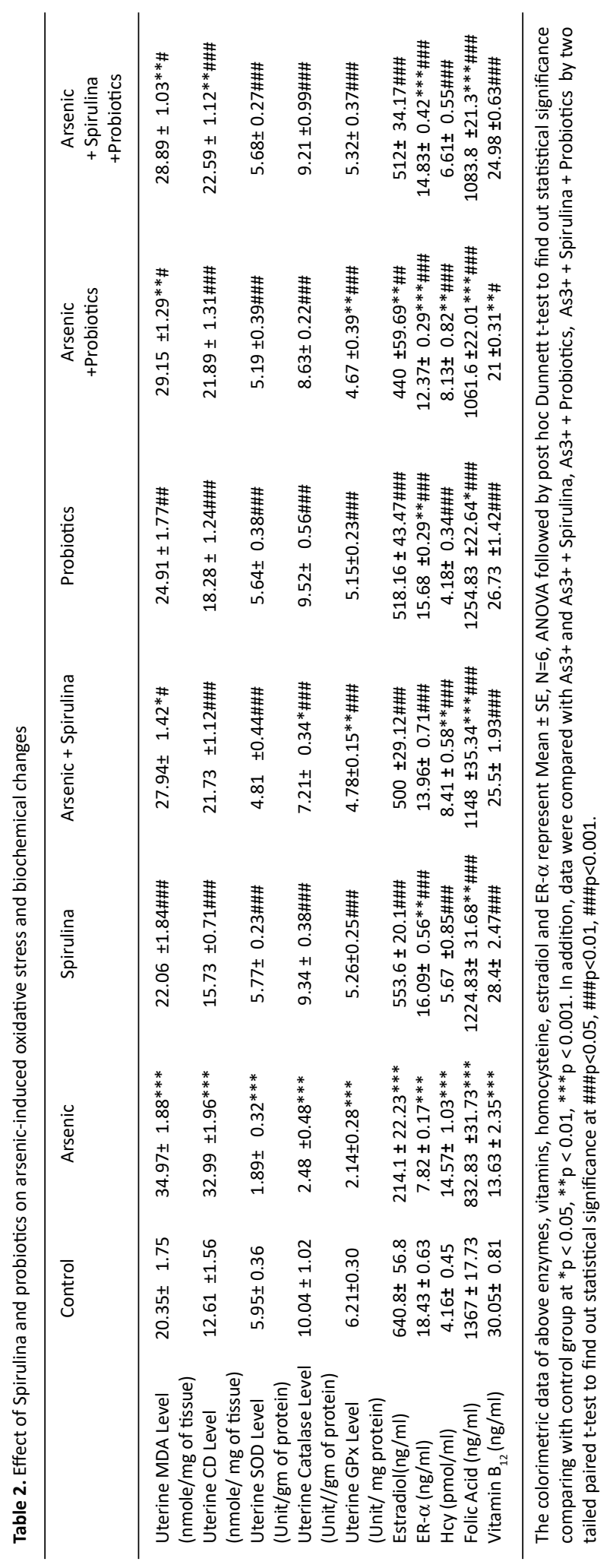




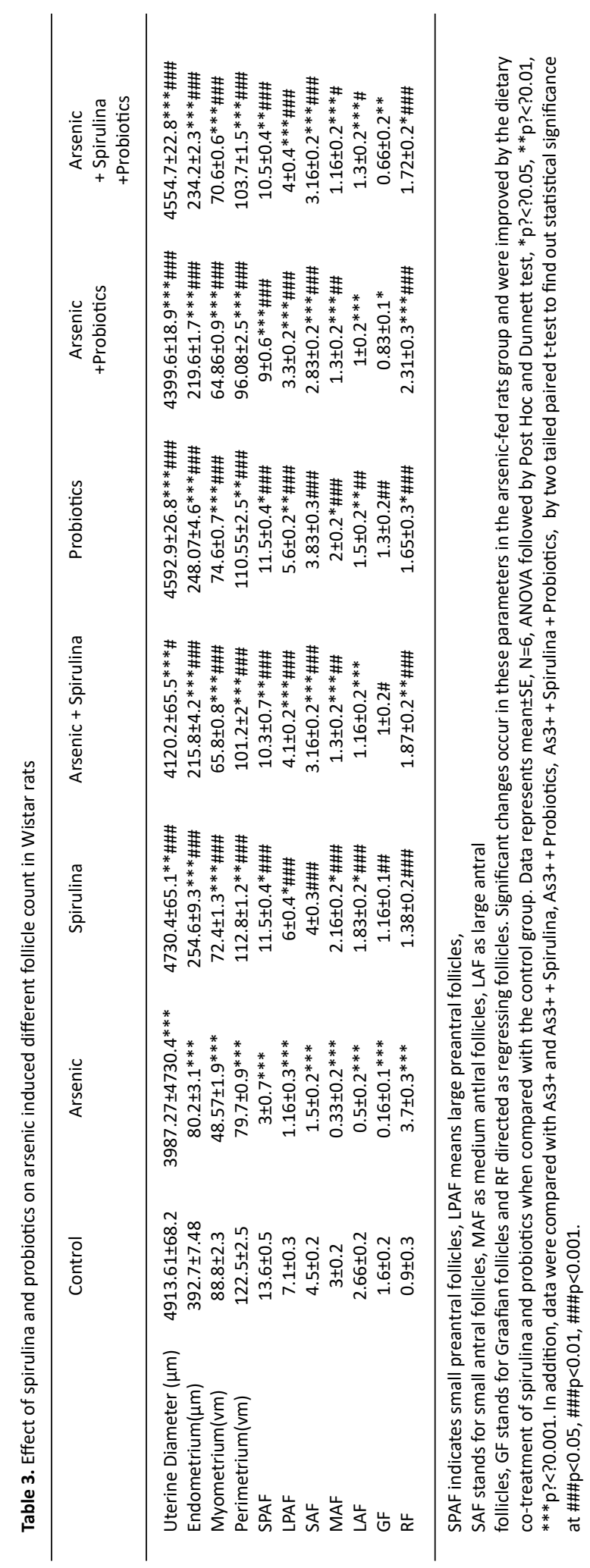




\section{Activities of antioxidant enzymes in uterus}

The activities of SOD, CAT and GPx in uterus were decreased significantly in arsenic treated group as compared to control group. Spirulina, probiotics and vehicle treated groups showed no significant differences in the activities of antioxidant enzymes as compared to the control group (Table 2 ).

We further evaluated uterine and ovarian SOD, catalase and GPx expression electrozymographically and it was observed a significantly reduced uterine and ovarian SOD, catalase and GPx expression in arsenic-exposed group compared to the control group (Fig. $1 \mathrm{~A}_{1}$ and $\left.1 A_{2} A, B, C\right)$.

Furthermore, the combined mode of dietary co-treatment with spirulina and probiotics had shown more intense recovery of uterine and ovarian catalase and GPx expression and nature of bands intensity was more prominent. Whereas in case of uterine and ovarian SOD, the band intensity was decreased in combined mode of dietary co-treatment with spirulina and probiotics but in case of individual treatment with spirulina and probiotics the band intensity was effectively increased.

\section{Serum LDH status}

Electrozymogram of serum LDH was used to focus the necrotic nature of the tissue (Fig. 1 $\left.A_{1} D\right)$. This release of the enzyme was significantly reduced by spirulina and probiotics alone or in combination with dietary mode in arsenic ingested rats as manifested from the weak expression of this necrotic marker.

\section{Status of measured vitamins}

Present study revealed that hyperhomocysteinemia $(p<0.001)$ followed by significantly decreased $(p<0.001)$ serum levels of folic acid and $B_{12}$ after arsenication. When arsenic combined with spirulina and probiotics resulted in the correction of the levels of Hcy, $B_{12}$ and folic acid along with lipid profile closed to the level of control groups (Table 2).

\section{Ovarian and Uterine histopathology}

Haematoxylin-Eosin stained ovarian tissue sections showed the significant degradation in the folliculogenesis with reduced numbers of growing follicles replaced by increasing numbers of regressing follicle in arsenic fed rats (Table3; Fig. $2 \mathrm{~B}_{2}$ ) in comparison with control and placebo groups (Table 3; Fig. 2B $\mathrm{B}_{1}, \mathrm{~B}_{3} \mathrm{~B}_{5}$ ). Uterine histomorphology revealed loss of secretory glands in arsenicated animals (Fig. 2A ) along with the thinning of uterine diameter (Table 3; Fig. $2 \mathrm{~A}_{2}$ ) with respect to control and placebo groups (Fig. 2A $A_{1} A_{3}, A_{5}$ ). Arsenicated rats when
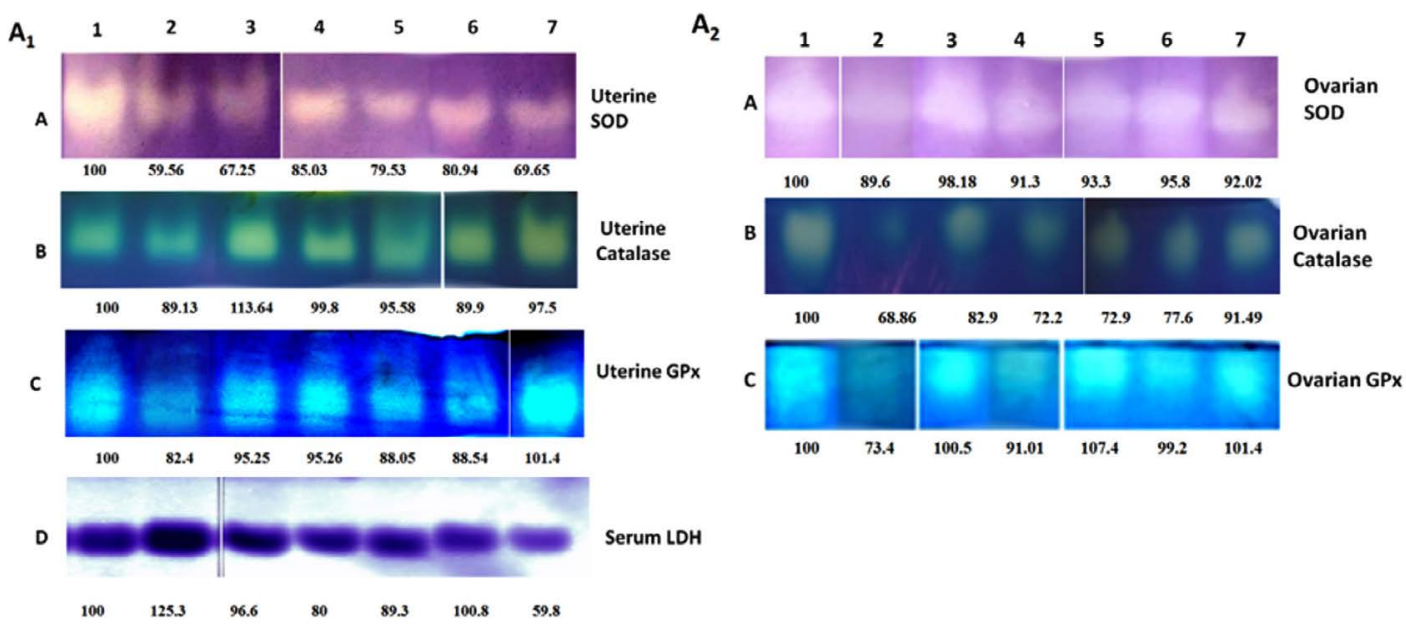

Fig. 1. Protective effect of spirulina and probiotics on uterine and ovarian tissue SOD, Catalase, GPx and serum $\mathrm{LDH}$ in $\mathrm{As}^{3+}$-intoxicated rats. (A, B and C) SOD, CAT and GPx expression in uterine tissue on native gel and (D) Serum profiles of $L D H$ activity was performed on agarose gel electrophoresis followed by substrate specific development of SOD, CAT, GPx and LDH bands. Lane distribution Lane 1: Control; Lane 2: Arsenic; Lane 3: Probiotics; Lane 4: Arsenic + Probiotics; Lane 5: Spirulina; Lane 6: Arsenic + Spirulina; Lane 7: Arsenic + Spirulina + Probiotics. 

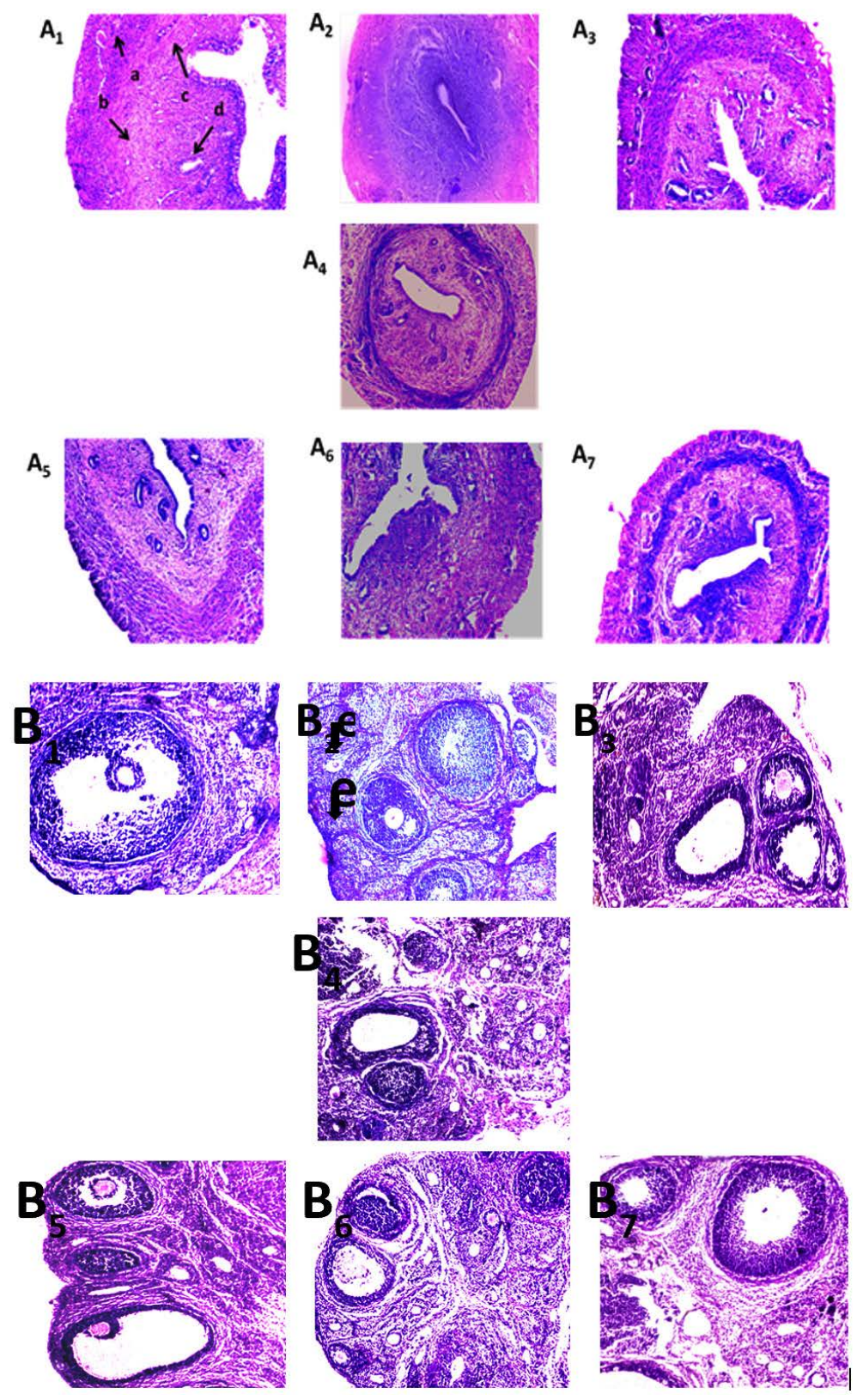

Fig. 2. Effect of spirulina and probiotics on histology of female reproductive organs. (A and $B$ ) Uterine and ovarian tissue were implanted in paraffin, serially sectioned laterally at $5 \mathrm{~nm}$, stained with eosin and haematoxylin (Harris) and observed under a microscope (magnification $\times 100$ ) to study the uterine (A) and ovarian (B) histo-architecture. Arrow indicates in slide " $d$ " the secretory glands and pictures showed in $A_{2}$ the remarkable loss of secretary cells of uterine tissue along with distortion of endometrial layer. The numbers of regressing follicles were increased in slide $\mathrm{B}_{2}$ in the arsenic exposed group where arrows indicate follicular atresia. Spirulina and probiotics dietay co-treatment significantly protected such arsenic induced ovarian (Figure $4 B_{4}, B_{6}, B_{7}$ ) and uterine (Figure $4 A_{4}, A_{6}, A_{7}$ ) disorders. Panel distribution; $A_{1}$ : vehicle treated control, $A_{2}$ : arsenic, $A_{3}$ : S. platensis, $A_{4}$ : arsenic $+S$. platensis., $A_{5}$ : probiotics, $A_{6}$ : arsenia+probiotics, $A_{7}$ : arsenic $+S$. platensis+ probiotics, $B_{1}$ : vehicle treated control, $B_{2}$ : arsenic, $B_{3}: S$. platensis, $\mathrm{B}_{4}$ : arsenic + S. platensis. $\mathrm{B}_{5}$ : probiotics, $\mathrm{B}_{6}$ : arsenia+probiotics, $\mathrm{B}_{7}$ : arsenic + S. platensis + probiotics (a- perimetrium, b- myometrium, c- endometrium, $d$ - secretory cells, e- atretic follicles). 
co-treated with spirulina and probiotics alone or in combination partially or moderately restored the number of growing follicles in the ovary with reducing number of regressing follicles (Table 3; Fig. $2 \mathrm{~B}_{4}, \mathrm{~B}_{6}, \mathrm{~B}_{7}$ ) compared to the vehicle treated control and the placebo groups. In uterus, dietary co-treatment of spirulina and probiotics alone or in combination were capable of maintaining the normal morphology of uterine tissue with an increasing number of uterine secretory glands (Table-3, Fig. . 2A). The thickness and diameter of uterine tissue were also restored towards normalcy following spirulina and probiotics dietary co-administration in arsenic-fed rats (Table-3).

\section{DISCUSSION}

This study demonstrates that strategic use of spirulina and probiotics may help in preventing arsenic-induced female reproductive toxicity to a significant extent. In this experiment our results showed a low-level expression of uterine and ovarian SOD, catalase and GPx in arsenic fed rats compared to the control (Fig. 1). These enzymes were considered as the first line of defense against oxidative injury at the cellular level. It was noted in the current study that spirulina was able to increase the activity of CAT and SOD after dietary intervntion with spirulina in $\mathrm{As}^{3+}$ fed rats. Spirulina has some positive action on these enzymes activity ${ }^{18}$ and the result is consistent with our previous report. Increased uterine MDA and CD levels in arsenic fed rats (Table 2 ) directed an increase in lipid peroxidation. The inhibitory effects of spirulina on lipid peroxidation were in conformity with the previous result ${ }^{19}$. Other investigators explored the therapeutic effects of spirulina on arsenic-induced male reproductive toxicity ${ }^{20}$. In this experiment electrozymographic evaluation of uterine and ovarian revealed an increased expression of SOD, catalase and GPx by following spirulina and probiotics dietary supplement in $\mathrm{As}^{3+}$ fed rats also indicated the attenuation of lipid peroxidation due to the decreased level of MDA and CD in this group.

Our results have been shown that suppression of $E_{2}$ (Fig. 3) and deterioration of follicular maturation (Fig. $2 \mathrm{~B}_{2}$ ) in response to As"I projected towards cellular degeneration in uterine layers (Fig. $2 \mathrm{~A}_{2}$ ). It has been reported that ovotoxic effects of arsenic also resulted in a loss of balance between oxidant and antioxidant systems leading to oxidative stress ${ }^{21}$. Reactive oxygen species play a critical role in the alteration of physiological and reproductive functions like oocyte maturation and luteolysis. Arsenic probably binds to estrogen receptor $(E R)$ and inhibits $E_{2}$ binding to the estrogen receptor alpha $(E R \alpha)^{22}$. Exposure to arsenic-caused a degradation of circulating levels of vitamin $B_{12}$ and folate, (Table 2). Dietary cotreatment with spirulina and probiotics to arsenic exposed rats exhibited a significant increase in $E R \alpha$ and $E_{2}$ signaling. The treated rats lost estrous cyclicity and focused persistent diestrus. Here in this study we predicted that consumption of healthy live microorganisms (lactic acid bacteria) with prebiotics (Spirulina platensis), may enhance ovarian and uterine histomorphology (Table 3 and Fig. 2) as well as hormonal status (Table 2).

Vitamin $B_{12}$ plays a key role as a cofactor for methionine synthase during the remethylation of Hcy to form methionine ${ }^{23}$. These two vitamins are indispensable to protect the reproductive organs from necrosis and have a protective role by diminishing serum LDH level (Fig. $1 A_{1} D$ ) as a consequence of an inverse relationship between the serum $\mathrm{LDH}$ activities and serum vitamin $\mathrm{B}_{12}$ folate levels ${ }^{24}$. Our observations indicated that the treatment with spirulina and probiotics restored ovarian and uterine weight by improving ES level. Dietary co-treatment of spirulina significantly mitigated arsenic-induced uterine oxidative stress and ovarian disorders. This overall defensive mechanism of spirulina might have terminated arsenic-primed protection of uterine and ovarian tissues from necrotic damage, as there was an improvement in the ovarian-uterine histoarchitecture (Fig. 2A and 2B) and this is further connected with the upregulation of gonadotrophin release and ovarian steroidogenesis ${ }^{25}$. In-addition spirulina has the capacity to bind with heavy metals; spirulina may demonstrate a chelating property to trap arsenic ${ }^{26}$. Methylation of arsenic in association with $\mathrm{S}$-adenosylmethionine involves methylcobalamin $\left(\mathrm{CH}_{3} \mathrm{~B}_{12}\right)$ and reduced glutathione for arsenic clearance and detoxification ${ }^{27}$. Arsenite S-adenosyl methionine methyl-transferase was isolated and characterized from spirulina ${ }^{28}$. An In vitro assay system demonstrated the arsenic methylation activity of spirulina ${ }^{28}$. This methylation 
process is the essential prerequisite for the removal of arsenic. Therefore, spirulina eventually promotes arsenic methylation and detoxification. In addition, previous observation suggested that probiotics are reported for its increased activity of antioxidative enzymes in the protection of cells against carcinogen-induced damage ${ }^{29}$. It has been shown that probiotics employ their self-protective effects against oxidative stress by re-establishment of the gut flora either by scavenging of oxidant compounds or by preventing intestinal free radical generation $^{30}$. Moreover, earlier studies have shown that lactic acid bacteria were shown to lengthen the resistance of the lipoprotein fractions to oxidation, reduce peroxidized lipoproteins, and improve total anti-oxidative activity ${ }^{31}$. The crucial mechanisms of probiotic anti-oxidant activity might be due to its metal-chelating properties. Lactic acid bacteria has been documented for its capability in the binding and removal of arsenic $^{32}$. In-addition it has been reported that Spirulina platensis extract was regarded as the best algal source for prebiotic as it has a greater stimulatory effect on the growth of probiotic bacteria $^{33}$. Moreover, previous study revealed that Spirulina platensis consumes nitrogen from the growth medium and releases extracellular carbohydrates and other growth substances which may be responsible for stimulating the growth of Lactobacilli33. A combination of probiotics and prebiotics constitutes a synbiotic, which can further stimulate and increase the survival of probiotic in the intestinal tract ${ }^{34}$. However, our study revealed that spiulina and probiotics might be a good choice in limiting arsenic mediated reproductive toxicity.

\section{CONCLUSION}

From above points we conclude that spirulina and probiotics have a challenging action against arsenic induced red-ox imbalance. This might be possible by reducing the level of lipid peroxidation, improving the antioxidant enzymes activities of the uterus, and by regulating ES signaling. Spirulina and probiotics might be regulating these activities by influencing the SAM pool especially by modulating B vitamins and Hcy in this pool and by influencing ER- $\alpha$ expression and sensitivity. Based on these results, it is explored that spiulina and pobiotics at $40 \mathrm{mg} / 100 \mathrm{~g}$ body weight and $2 \mathrm{mg} / 100 \mathrm{~g}$ body weight reflected a better protective effect against reproductive damages in arsenic fed Wistar rats $(1 \mathrm{mg} / 100 \mathrm{~g}$ body weight. Dietary co-treatment of spirulina and probiotics have a potential role to improve uterine and ovarian anti-oxidant defense system and ovarian-uterine histoarchitecture either by their chelating action with arsenic or by sustaining B vitamins.

\section{ACKNOWLEDGMENTS}

None

\section{CONFLICT OF INTEREST}

The authors declare that there is no conflict of interest.

\section{AUTHORS' CONTRIBUTION}

SK, SC and SC conceived and designed the study. SK and SC performed the experiments. SK and SC analyzed and interpreted the data. SK and SC contributed resources. SK and SC supervised and revised the manuscript.

\section{FUNDING}

None

\section{DATA AVAILABILITY}

All datasets generated or analyzed during this study are included in the manuscript.

\section{ETHICS STATEMENT}

This study was carried out in accordance with the following the standard protocol of Vidyasagar University's ethical guidelines (ethical clearance No. IEC/7-2/C-2/16, dated 26 August 2016).

\section{REFERENCES}

1. Sarkar M., Chaudhuri G.R., Chattopadhyay A., Biswas N.M. Effect of sodium arsenite on spermatogenesis, plasma gonadotrophins and testosterone in rats. Asian journal of andrology, 2003; 5: 27-32.

2. Milton A.H., Smith W., Rahman B., Hasan Z., Kulsum U., Dear K., Rakibuddin M., Ali A. Chronic arsenic exposure and adverse pregnancy outcomes in Bangladesh. Epidemiology, 2005; 16: 82-86.

3. Chattopadhyay S., Ghosh S., Chaki S., Debnath J., Ghosh D. Effect of sodium arsenite on plasma levels of gonadotrophins and ovarian stero-idogenesis in mature albino rats: duration dependent response. J. Toxicol. Sci., 1999; 24: 425-431. 
4. Bhat V.B., Madyastha K.M. Scavenging of peroxynitrite by phycocyanin and phycocyanobilin from Spirulina platensis: protection against oxidative damage to DNA. Biochemical and Biophysical Research Communications, 2001; 285: 262-266.

5. Lissi E., Pizarro A., Aspee M.A., Romay C. Kinetics of phycocyanine bilin groups destruction by peroxyl radicals. Free Radical Biology and Medicine, 2000; 28: 1051-1055.

6. Rahman M.H., Islam A.Z. M. M., Sikder S. Dynamics of Spirulina in promoting health benefits for arsenicosis patients. J Bangladesh Coll Phys Surg, 2008; 26: 14-21.

7. FAO/WHO: Health and nutritional properties of probiotics in food including powder milk with live lactic acid bacteria. www.fao.org. 2001.

8. Stecchini M.L., Del Torre M., Munari M. Determination of peroxy radical-scavenging of lactic acid bacteria. Int. J. Food Microbiol., 2001; 64: 183-188.

9. Kullisaar T., Zilmer M., Mikelsaar M., Vihalemm T., Annuk H., Kairane C., Kilk A. Two antioxidative lactobacilli strains as promising probiotics. Int. J. Food Microbia.l, 2002; 72: 215-224.

10. Devasagayam T.P., Boloor K.K, Ramasarma T. Methods for estimating lipid peroxidation: an analysis of merits and demerits. Ind J Biochem. Biophy, 2003; 40: 300-308.

11. Kumar A. 2012. Effect of simuastation on paraxonase 1 (PON1) activity and oxidation stress In. pp. 105-109. Kumar A (ed) Significance of lipid profile assay as diagnostic and prognostic tool. CreateSpace Independent Publishing Platform, California.

12. Pattichis K., Louca L.L., Glover V. Quantitation of Soluble Superoxide Dismutase in Rat Striata, Based on the Inhibition of Nitrite Formation from Hydroxylammonium Chloride. Anal biochem., 1994; 221:428-431.

13. Hadwan M.H. New method for assessment of serum catalase activity. Indian J. Sci. Technol, 2016; 9: 1-5.

14. Paglia D.E., Valentine W.N. Studies on quantitative and qualitative characterization of erythrocyte glutathione peroxidise. J. Lab. Clin. Med., 1967; 70: 158-169.

15. Weydert C.J., Cullen J.J. Measurement of superoxide dismutase catalase, and glutathione peroxidase in cultured cells and tissue. Nat. Protoc., 2010; 5: 51-66.

16. Liu J., Du J., Zhang Y., Sun W., Smith B.J., Oberley L. W. Suppression of the malignant phenotype in pancreatic cancer by the overexpression of phospholipid hydroperoxide glutathione peroxidise. Hum. Gene Ther, 2006; 17: 105-116.

17. Brandt R.B, Laux J.E., Spainhour S.E., Kline E.S. Lactate dehydrogenase in rat mitochondria. Arch Biochem Biophy , 1987; 259: 412-22.

18. Ismail M., Hossain M.F., Tanu A.R., Shekhar H.U. Effect of Spirulina Intervention on Oxidative Stress, Antioxidant Status, and Lipid Profile in Chronic Obstructive Pulmonary Disease Patients. Bio. Med. Research International, 2015; 2015: 1-7.

19. Khatun S., Maity M., Perveen H., Dash M., Chattopadhyay S. Spirulina platensis ameliorates arsenicmediated uterine damage and ovarian steroidogenic disorder. FACETS, 2018; 3: 1-18.

20. Bashandy S.A.E., Awdan S.A.E., Ebaid H., Alhazza I.M.
Antioxidant potential of Spirulina platensis mitigates oxidative stress and reprotoxicity induced by sodium arsenite in male rats. Oxidative Medicine and Cellular Longevity, 2015; 2016: 7174351.

21. Cassano E., Tosto L., Balestrieri M., Zicarelli L., Abrescia P. Antioxidant defense in the follicular fluid of water buffalo. Cell. Physiol. Biochem., 1999; 9: 106-16.

22. Bae-Jump V.L., Zhou C., Boggess J.F., Gehrig P.A. Arsenic trioxide $\left(\mathrm{As}_{2} \mathrm{O}_{3}\right)$ inhibits expression of estrogen receptoralpha through regulation of the mitogen-activated protein kinase (MAPK) pathway in endometrial cancer cells. Reprod. Sci., 2008; 15: 1011-1017.

23. Sumona B., Sheetal S., Anil M., Suvarna P. Comparative evaluation of serum folic acid levels in smokers and non-smokers with chronic periodontitis. Bangladesh J. of Med. Sci., 2011; 10: 83-90.

24. Maity M., Perveen H., Dash M., Jana S., Khatun S., Dey A., Mandal A.K., Chattopadhyay S. Arjunolic acid improves the serum level of vitamin $B_{12}$ and folate in the process of the attenuation of arsenic-induced uterine oxidative stress. Biol. Tres. Elem. Res., 2017; 182: 78-90.

25. Kulin H.E., Reiter E.O. Gonadotropins during childhood and adolescence: a review. Pediatrics, 1973; 51: 260-271.

26. Plazinski W. Binding of heavy metals by algal biosorbents, theoreticalmodels of kinetics, equilibria and thermodynamics. Advances in Colloid and Interface Science, 2013; 197-198: 58-67.

27. Nakamura K. 2011. Biomimetic and bio-inspired catalytic system for arsenic detoxification: bioinspired catalysts with vitamin- $B_{12}$ cofactor. pp. 213-228. In On biomimetics. Edited by L Pramatarova. Intech Open, Rijeka, Croatia.

28. Guo Y., Xue X., Yan Y., Zhu Y., Yang G., Ye J. Arsenic methylation by an arsenite S-adenosyl methioninemethyl transferase from Spirulina platensis. Journal of Environmental Sciences, 2016; 49: 162-168.

29. Kumar M., Kumar A., Nagpal R., Mohania D., Behare P., Verma V., et al. Cancer-preventing attributes of probiotics: an update. Int J Food Sci Nutr, 2010; 61: 473-496.

30. Nardone G., Compare D., Liguori E., Di Mauro V., Rocco A., Barone M., Napoli A., Lapi D., lovene M.R., Colantuoni A. Protective effects of Lactobacillus paracasei F19 in a rat model of oxidative and metabolic hepatic injury. Am J Physiol Gastrointest Liver Physiol, 2010; 299: G669-G676.

31. Lin M.Y., Yen C.L. Antioxidative ability of lactic acid bacteria. Agric. Food Chem., 1999; 47: 1460-1466.

32. Kumar R., Kumari S., Kumari P., Kumar A., Ali M., Niraj P.K., Ghosh A. In vitro elimination of arsenic from water through Lactobacillus sporogenes. Eur. J. Pharma. Med. Res., 2017; 4:581-585.

33. Parada J.L., Zulpa D.C.G, Zaccaro D.M.M., Storni D.C.M. Lactic acid bacteria growth promoters from Spirulina platensis. Int. J. Food Microbiol., 1998; 45: 225-228.

34. Gourbeyre P., Denery S., Bodinier M. Probiotics, prebiotics, and synbiotics: impact on the gut immune system and allergic reactions. J. Leukoc. Biol., 2011; 89: 685-695. 